\title{
Development of Different Strategies for the Clean-Up of Polychlorinated Biphenyls (PCBs) Congeners Using Pressurized Liquid Extraction
}

\author{
Amal Al-Rashdan*, Murad I. H. Helaleh \\ Kuwait Institute for Scientific Research, Deputy Director General Office for Research, Safat, Kuwait. \\ Email: *mrhelala@yahoo.com
}

Received October $4^{\text {th }}, 2012$; revised November $5^{\text {th }}, 2012$; accepted December $6^{\text {th }}, 2012$

\begin{abstract}
The extracted fish samples (w/w) using pressurized liquid extraction (PLE) were cleaned up by applying different adsorbent materials such as: combination of acidic/basic silica and alumina, florisil, and silica gel either alone or in combination with another sort of sorbent. Different solvents such as hexane (H), dichloromethane (DCM), with different compositions were used to elute the PCBs target compounds from the spiked fish samples. Overall the mean percentage recoveries for all PCBs congeners using PLE were ranging from $78.6 \%$ to $98.7 \%$; from $79.4 \%$ to $91.8 \%$; from $65.8 \%$ to $104.5 \%$ and from $82.4 \%$ to $100.9 \%$ for cases A, B, C, D and E, respectively. However, the overall mean percentage recoveries for the 13C-PCBs surrogate including: $101,138,153,180$ and 209 were ranging from $88.2 \%$ to $97.6 \%$; from $79.4 \%$ to $90.2 \%$, from $88.3 \%$ to $96.4 \%$, from $79.8 \%$ to $90.4 \%$ and from $83.9 \%$ to $95.9 \%$, for cases A, B, C, D and E, respectively. The limits of detection of the proposed method were varied from 0.01 to $0.28 \mathrm{ng} / \mathrm{g}(\mathrm{w} / \mathrm{w})$ for different PCBs congeners. The proposed method has linear dynamic range from $21.5 \mathrm{ng} / \mathrm{g}$ to $109 \mathrm{ng} / \mathrm{g}$. This method was applied to fish samples for the determination of the target PCBs components.
\end{abstract}

Keywords: Polychlorinated Biphenyls (PCBs); Pressurized Liquid Extraction (PLE); Adsorbent Materials; Gel Permeation Chromatography (GPC); Negative Chemical Ionization (NCI); Marine Sample

\section{Introduction}

Persistent Organic Pollutants (POPs) consist of heterogeneous groups including, polychlorinated biphenyls (PCBs), organo-chlorinated pesticides (OCPs), and other organic pollutants [1]. POPs are characterized by high chemical, biological stability and lipophilicity, which makes POPs persist in the environment and bio-accumulate within the food chain [2]. POPs are toxic chemicals that have the capability to stay stable in the environment over long period of time. In the year 2001 Stockholm Convention, the polychlorinated biphenyls (PCBs) organochlorinated pesticides (OCPs) were given special attention and thus were included in the so called "dirty dozen" [3].

It is to be noted that accuracy in generating data is critical in decision making process. Monitoring of PCBs plays a vital role in determining environmental contamination. Therefore, obtaining information for regulatory purpose is needed. Clean-up of the extracted organic compounds looks to be interesting by applying different sorts of adsorbents which leads to strongly biding of the analytes onto adsorbent portion or by their interaction with

${ }^{*}$ Corresponding author. matrix in order to recover the maximum amount of analytes from substrate. Sample treatment consists of two steps: one step is to destroy the lipids by using SX3-300 Bio-beads (GPC) and the second step is the clean-up step that is performed by using different adsorbents.

Pressurized liquid extraction (PLE) found to fulfills the least evolve parts of the analytical extraction procedures since it has the advantage of short extraction times combined with automation and low solvent consumption. Furthermore, the technique is simple and adopted to a large number of applications. Extraction procedures in PLEs were effectively used to extract number of POPs such as PCBs [4-6]. Using pressurized liquid extraction (PLE) is widely used for food, feed extraction and in environmental POP investigations since the mid 1990s $[2,3,7]$. However, the United States Environmental Agency (US EPA) adopted the PLE technique in 1995 (US EPA Method 3545) [8]. PLE has been used for the extraction of PCBs in whole ground carp [9], muscle tissue [9], and oyster tissue [10]. Numerous applications of PLE for the extraction of POPs from biota samples have been reported in the past few years [11-14]. Suchan et al. [14] 
extracted OCPs and PCBs from fish fillets applying PLE using two different solvent mixtures (H:DCM; $1: 1, \mathrm{v} / \mathrm{v}$ ) and (H:acetone; 4:1, v/v) and they compared PLE with conventional soxhlet extraction with both solvents tested and they found that PLE was comparable to soxhlet. Recently, Saito et al. [15] applied PLE to extract POPs (PCBs, PBDEs, OCPs, etc.) from biological tissues. Jiang et al. [16] reported the use of PLE to extract several POPs (PCBs, PCDDs/DFs and PCNs) from freezedried seafood samples such as: fish, crab, shrimp, bivalves and cephalopods.

The extracts of bald eagle tissue for PCBs, OCPs and polychlorinated dibenzo-p-dioxins and dibenzofurans (PCDD/DFs) were subjected to silica gel, alumina, acidic silica and activated carbon column for clean-up and fractionation [17]. Activated silica was used for the fractionation containing PCBs, OCPs, and Poly Aromatic Hydrocarbons (PAHs) from the mussel extract $[18,19]$.

The analytical methods used for the determination of PCBs in environmental samples (fish) consist of several steps for sampling, sample treatment, fractionation and detection of targeted compounds. The sample treatment is multi-steps procedure that its basic concept is to convert a complex matrix into a sample that is suitable for the analysis.

Regardless, the technique that it is used for extraction with different types of components such as, lipids, pigments are mostly present in the extract and must be removed in order to identify and to quantify lower levels of analytes and to reduce the deterioration of chromatograms. Several methods of clean-up have been developed in order to remove the co-extracted matrix and minimize their negative effects. The necessity of the clean-up step is to completely remove the bulk of the co-extracted material, as well as those compounds that behave the same as to the analytes that could potentially interfere in the final quantification.

Therefore, the main target of this study is to achieve the followings: 1) to extract the PCBs congeners from the matrix; 2) to remove the un-wanted organic compounds, which may interfere with the compounds of interest; 3 ) to provide a suitable adsorbent material free from interferences (clean-up); 4) finally to convert the extracted analytes from the matrix into a more suitable concentration level. A comparative study using different types of adsorbents was conducted in order to improve the sample preparations without sacrificing the quality of measurements (sensitivity, accuracy, precision, repeatability, reproducibility and recovery) in fish samples for the analyses of polychlorinated biphenyls (PCBs). Moreover, a GC-MS (NCI) method was applied for the analysis of PCBs.

\section{Experimental}

\subsection{Standards, Chemicals and Samples}

The PCBs (EC-4133) contain the following congener numbers: 2,4,4',5-tetraCB (74); 2,3', 4',5-tetraCB (70); 2,2',3,5',6-pentaCB (95); 2,2',4,5,5'-pentaCB (101); 2,2',4,4',5-pentaCB (99); 2,2',3,4,5'-pentaCB (87); 2,,3,3', 4',6-pentaCB (110); 2,2',3,5,5',6-hexaCB (151); 2,2',3,4', 5',6-hexaCB (149); 2,3',4,4',5-pentaCB (118); 2,2',4,4',5,5'-hexaCB (153); 2,3,3',4,4'-pentaCB (105); 2,2',3,4,4', ','-hexaCB (138); 2,2',3,3',4,6'-hexaCB (132); $2,, 3,3^{\prime},, 4,4^{\prime}, 6$-hexaCB (158); 2,2,',3,4',5,5',6-heptaCB (187); 2,2,',3,4,4',5',6-heptaCB (183); 2,2',3,3',4,4'-hexaCB (128); 2,2',3,3',4',5,6-heptaCB (177); 2,2',3,3',4,4',6heptaCB (171); 2,3,3',4,4',5-hexaCB (156); 2, 2',3,4,4',5,5'heptaCB (180); 2,3,3',4,4',5',6-heptaCB (191); 3,3',4, 4',5,5'-hexaCB (169); 2,2',3,3',4,4',5-heptaCB (170); 2,2',3,3',4,5,5',6,6'-nonaCB (208); 2,2',3,3',4,4',5,6'-octaCB (195); 2,2',3,3',4,4',5,5'-octaCB (194); 2,2',3,3',4,4', $5,5^{\prime}, 6$-nonaCB (206) and decaCB (209). A ${ }^{13}$ C-labeled PCB mixture (EC-4058) was obtained from Cambridge Isotope Laboratories, and contained the following congener numbers: $2,2^{\prime}, 3,4,4^{\prime}, 5^{\prime}$-hexaCB $\left({ }^{13} \mathrm{C}_{12}, 99 \%\right)(138)$; $2,2^{\prime}, 4,4^{\prime}, 5,5^{\prime}$-hexaCB $\left({ }^{13} \mathrm{C}_{12}, 99 \%\right)(153) ; 2,2^{\prime}, 3,4,4^{\prime}, 5$, 5'-pentaCB $\left({ }^{13} \mathrm{C}_{12}, 99 \%\right)(180)$; and decaCB $\left({ }^{13} \mathrm{C}_{12}, 99 \%\right)$ (209). A standard stock solution of $128.8 \mathrm{ng} / \mathrm{ml}$ was used to prepare the standard working calibration solutions for most of the PCB compounds.

All solvents were pesticide-grade. Hexane $(\mathrm{H})$ and dichloromethane (DCM) were supplied by Merck (Darmstadt, Germany). Nitrogen gas was used to concentrate the extract. The evaporator (Heidolph-Verwenden, Germany) and SX-3 Bio-Beads (200 - 400 mesh) were purchased from Bio-Rad Laboratories $\mathrm{GmbH}$, in Munich, Germany. Anhydrous sodium sulfate (EMD-Chemical, Darmstadt, Germany) was purchased from Sigma Aldrich Chemie GmbH in Steinhein, Germany. Silica gel (100 - 200 mesh) was obtained from Aldrich (Steinhein, Germany). Aluminum oxide (70 - 230) and florisil were obtained from VWR-Baker. Fish samples were collected from the local market in Kuwait to validate the method on real samples.

\subsection{Instrumentation}

PCBs were quantified on an Agilent 5973 inert mass selective detector, and on an Agilent Technology 6890 network gas chromatography (GC) system coupled with mass spectrometry (MS) with a negative chemical ionization (NCI) ion source. The system was operated in selective ion monitoring (SIM) mode, and $1 \mu l$ of sample solution was injected into the GC in the auto-sampler's splitless mode. The capillary column used was a DB-5MS (30 m 
$\times 0.25 \mathrm{~mm}$ I.D., $0.25 \mu \mathrm{m}$ film thickness). The initial oven temperature was $100^{\circ} \mathrm{C}$, which was held constant for 0.5 min. It was then increased to $140^{\circ} \mathrm{C}$ at a rate of $20^{\circ} \mathrm{C} / \mathrm{min}$, with no holding time, followed by increase in temperature to $200^{\circ} \mathrm{C}$ at a rate of $4^{\circ} \mathrm{C} / \mathrm{min}$ with 13 min holding time, and finally increase in temperature to $270^{\circ} \mathrm{C}$ at a rate of $4^{\circ} \mathrm{C} / \mathrm{min}$, where it was maintained for $4 \mathrm{~min}$. The helium carrier gas flow rate was maintained at 1.1 $\mathrm{ml} / \mathrm{min}$. The transfer line temperature of the GC-MS interface and the ion source temperature were held at $300^{\circ} \mathrm{C}$ and $280^{\circ} \mathrm{C}$, respectively. The MS was conducted in the NCI mode with methane as the reagent gas $(40$ $\mathrm{ml} / \mathrm{min}$ ).

\subsection{Sample Preparation and Purification}

The edible portions of the fish sample were homogenized. The wet fish sample $(5 \mathrm{~g})$ was mixed with anhydrous sodium sulfate to reduce the amount of water and then it was extracted using PLE system. The wet fish samples were grinded to small sizes, which might facilitate the analyte transport to the solvent particle surface. The grinded samples were filled into the cell and the dead volume of the cell was filled with intermatrices, such as hydromatrix. The extraction was performed with $10 \%$ (H:DCM). The extract was concentrated by a rotary evaporator to $10 \mathrm{ml}$. The samples were cleaned with gel permeation chromatography (GPC), GPC column was packed with $12 \mathrm{~g} \mathrm{SX}-3$ bio-beads and filled with 1:1 ( hexane: dichloromethane), when it is not used. $100 \mathrm{ml}$ [H:DCM (1:1)] was used to elute the extract, and GPC column was used to remove less than $1.0 \%$ fat. The first $45 \mathrm{ml}$ was discarded and the remaining solvent was collected. The extract was concentrated to appropriate volume $(1 \mathrm{ml})$ using rotary-vapor concentrator and finally the $1 \mathrm{ml}$ goes under gentle stream of clean dry nitrogen. The extract then was subjected to different layer of adsorbents (eight adsorbents) as described in Table 1. The column was plugged with glass wool. A slurry method was used to fill the column. The multilayer column (glass column with
$15 \mathrm{~mm}$ inner diameter and $30 \mathrm{~cm}$ long) was packed from top to bottom. Each column was prepared freshly before its use as part of quality control procedures. Elution of samples was carried out at a rate of about $1 \mathrm{ml} / \mathrm{min}$, using different solvent mixtures as shown in Table 1.

\subsection{Pressurized Liquid Extraction (PLE)}

Automated PLE extraction was used (FMS, Waltham, Massachusetts, USA). A stainless-steel extraction cell was supported with Teflon end-caps and filters. The PLE system was controlled by means of a PC using DMS 6000 software that shows the real time, temperature and pressure. The pump, flow rate, solvent time, valves status and cooling were adjusted during the extraction run by the software. Extraction was carried out at a temperature above the solvent's boiling point and under its pressure to maintain the liquid state of the organic solvent, which keeps the solvent below its critical condition, as well as maintaining its viscosity and its salvation power. Under the selected conditions, the extraction efficiency was enhanced, and the amount of solvent required was minimized. Following is the PLE program that was utilized in the effective extraction of the PCBs:

1) Filling cells with solvent (input: open; output: open); time $=2 \mathrm{~min}$;

2) Pressurizing cell (input: open; output: close); time = $1.0 \mathrm{~min}$

3) Heating and maintaining pressure (input: close; output: close); temp. $=120^{\circ} \mathrm{C}$; time $=30 \mathrm{~min}$;

4) Cooling (pump: off; input: close; output: close); time $=15 \mathrm{~min} ;$ fan $=$ on;

5) Depressurizing (input: close; output: open); time= $0.02 \mathrm{~min}$;

6) Rinsing sample (input: open; output: open); time= $2.5 \mathrm{~min}$;

7) Purging with N2 (N2: 35 psi) (input: close; output: open); time = $1.0 \mathrm{~min}$;

8) Opening all valves; Time $=0.02 \mathrm{~min}$.

Table 1. Type of adsorbent; eluent solvent mixture used in the elution of PCBs.

\begin{tabular}{|c|c|c|c|c|}
\hline $\begin{array}{l}\text { Case } \\
\text { No. }\end{array}$ & Adsorbent & Solvent mixture & $\begin{array}{l}\text { Spiked PCBs } \\
(\mathrm{ng} / \mathrm{g})\end{array}$ & $\begin{array}{c}\text { Spiked }{ }^{13} \text { C-PCBs }(\mathrm{ng} / \mathrm{g}) \\
+ \text { recoveries }(\%)\end{array}$ \\
\hline A. & $\begin{array}{l}10 \mathrm{~g} \text { acidic silica }(24 \%)+10 \mathrm{~g} \text { basic } \\
\text { silica }(1 \mathrm{~N})+5 \mathrm{~g} \mathrm{Al}_{2} \mathrm{O}_{3}+2 \mathrm{~g} \mathrm{Na}_{2} \mathrm{SO}_{4}\end{array}$ & $60 \mathrm{ml} \mathrm{H}: \mathrm{DCM}(1: 1 ; \mathrm{v} / \mathrm{v})$ & 21.8 & $\begin{array}{c}24 \\
(88.2-97.6)\end{array}$ \\
\hline B. & $6 \mathrm{~g}$ silica gel $+2 \mathrm{~g} \mathrm{Na}_{2} \mathrm{SO}_{4}$ & $135 \mathrm{H}+15 \mathrm{ml} \mathrm{DCM}$ & 21.8 & $\begin{array}{c}24 \\
(79.4-90.2)\end{array}$ \\
\hline C. & $17 \mathrm{~g}$ florisil $+2 \mathrm{~g} \mathrm{Na}_{2} \mathrm{SO}_{4}$ & $\begin{array}{c}70 \mathrm{ml} \mathrm{H}+50 \mathrm{ml} \mathrm{H}: \mathrm{DCM} ; 70: 30 \\
\text { v/v+ } 40 \mathrm{ml} \mathrm{DCM}\end{array}$ & 54.5 & $\begin{array}{c}24 \\
(88.3-96.4)\end{array}$ \\
\hline D. & $17 \mathrm{~g}$ florisil $+2 \mathrm{~g} \mathrm{Na}_{2} \mathrm{SO}_{4}$ & $70 \mathrm{ml} \mathrm{H}+50 \mathrm{ml} \mathrm{H:DCM} ;(1: 1 ; \mathrm{v} / \mathrm{v})$ & 21.8 & $\begin{array}{c}24 \\
(79.8-90.4)\end{array}$ \\
\hline E. & $17 \mathrm{~g}$ florisil $+2 \mathrm{~g} \mathrm{Na}_{2} \mathrm{SO}_{4}$ & $70 \mathrm{ml} \mathrm{H}+50 \mathrm{ml}(\mathrm{DCM}: \mathrm{H} ; 10 \%)$ & 21.8 & $\begin{array}{c}24 \\
(83.9-95.9)\end{array}$ \\
\hline
\end{tabular}


The PLE system was washed after 2 sets of extraction run using the following program:

1) Filling column (input: open; output: open); time = $2.5 \mathrm{~min}$

2) Flushing bypass (input: open; output: close); time $=$ $1.0 \mathrm{~min}$

3) Depressurizing (input: close; output: open); time = $0.02 \mathrm{~min}$;

4) Purging with N2 (input: close; output: open); time = $0.02 \mathrm{~min}$;

5) Ending stage (all are closed).

\section{Results and Discussion}

\subsection{Extraction Solvent, Adsorbents Column and Elution Solvent for the Clean-Up}

Several facts have to be considered when choosing extraction solvent, such as: physical chemical properties (i.e. polarity, boiling point, density and toxicity [20]). However, when using different solvent extraction mixture for the fish sample, calculating the recoveries of the targeted compounds with respect to the solvent mixture used for the extraction, there was no significant differrences found between the results obtained with the PLE method. The polarity of the used extraction solvent mixture, plays a role in decreasing the turbidity and the content of matrix pigment in the extracted samples [21].

In general, the solvent selection is important for the extraction of contaminants from the matrix of interest. Hexane, dichloromethane and acetone with different combinations were selected usually for the extraction and clean-up of PCBs, due to the fact that they are frequently used to extract PCBs from biotic and abiotic samples. However, with all the solvents combinations used in PLE extraction and clean-up of the extract resulted in comparably good recoveries of all $\mathrm{PCBs}$ which were above $70 \%$ and close to $100 \%$ for most solvents compositions tested. This shows that all the extraction of PCBs was completely recovered under the PLE and clean-up conditions.

Different chromatographic columns with different solvent mixtures were studied, in order to find the best adsorbent for the elution of PCBs congeners. The adsorbent materials, the solvent composition which were used in the experimental test for PCBs were presented in Table 1. Using acidic and basic silica column showed good recoveries for all the PCBs congeners (Figure 1, case A). The $6 \mathrm{~g}$ silica with $135 \mathrm{ml}$ Hexane $+15 \mathrm{ml}$ DCM, showed good recoveries, as shown in Figure 1 (case B). Using $17 \mathrm{~g}$ florisil and $70 \mathrm{ml}$ hexane $+50 \mathrm{ml}$ (H:DCM; $70: 30, \mathrm{v} / \mathrm{v})+40 \mathrm{ml}$ DCM, the recoveries of the spiked sample were varied from $97.4 \%$ to $91.8 \%$ (Figure 1, case C). When using florisil (17 g), with different eluant com- positions: 1) $70 \mathrm{ml}$ hexane and $50 \mathrm{ml}$ [DCM:H (50\%)]; 2) $70 \mathrm{ml}$ hexane $+50 \mathrm{ml}[10 \%(\mathrm{H}: \mathrm{DCM})]$, a comparative recoveries were obtained for most of PCBs as shown in (Figure 1, case D and E).

Under the PLE extraction and the clean-up parameters in the present study, recoveries of PCBs were typically excellent over the entire conditions investigated. The use of glass column sorbents for the clean-up method that is filled with adsorbent as described in Table 1. The results showed that clean-up elution using any of the adsorbents from case $\mathrm{A}$ to $\mathrm{E}$, the recoveries were comparable and satisfactory. However, the chromatograms for all of the cleaned samples were well resolved and they were having less background noise. Moreover, the optimal solvent for the clean-up elution was also investigated as described in Table 1. The results of the recoveries were also satisfactory for all PCBs congeners as shown from case A to case E.

\subsection{Effect of PLE Operating Parameters}

Temperature is an important factor in PLE to enhance the recoveries. Increasing temperature has positive effects on increasing the extraction efficiency of the analytes, leading to improve the mass transfer of the analytes and consequently cause the analytes to increase their recoveries. Moreover, increasing temperature leads to reduce the surface tension and the viscosity of the solvent, which facilitate and improve the sample wetting and matrix penetration [10]. PLE is a solid-liquid extraction step, taking place in close-vessels at elevated temperature and pressure. The pressure is applied to maintain the organic solvents in its liquid state. The temperature should be above the solvents' atmospheric boiling points. These conditions allow the solvents to be below their critical conditions, but also enhance their salvation power and lower their viscosities, which lead to a higher diffusion rate for the extraction of the analytes. Applying all these conditions, the extraction efficiency is increased and the solvent needed is minimized.

Time is one of the important parameters to be considered and therefore, the time devoted to the optimization and development of the extraction procedure can be reduced. However, PLE is an attractive alternative method compared with conventional soxhlet method, due to the following reasons; its fast, less solvent consumption, and sequentially it allows extracting 6 samples with the use of different sample vessels sizes.

In general, increasing temperature $\left(>140^{\circ} \mathrm{C}\right)$ causes serious disruption in the solute-matrix interactions resulting from Van der Waals forces, hydrogen bonding and or dipole attractions. These interactions could affect the recovery percentage obtained [10]. 

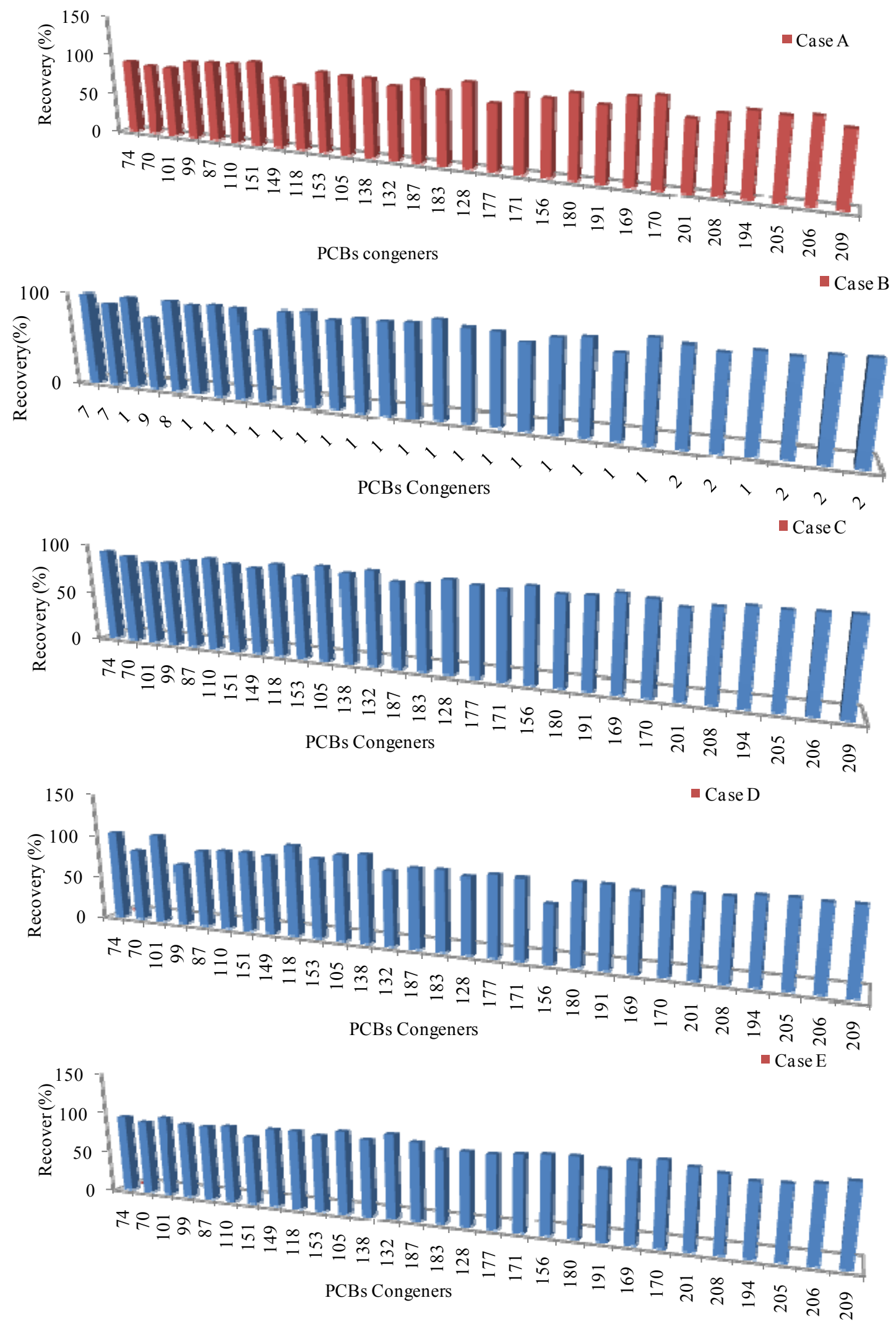

Figure 1. Recoveries percentages of the selected PCBs were obtained by spiking the standards before the extraction, using different adsorbents and solvent mixtures. The detail of each case is described in Table 1. 
The extraction recoveries were decreased at temperatures above $140^{\circ} \mathrm{C}$ for most of the compounds. Temperatures above $140^{\circ} \mathrm{C}$ could result in the co-extraction of contaminants, which would affect the GC/MS (NCI) analysis. At a higher temperatures $\left(>140^{\circ} \mathrm{C}\right)$, the chromatograms showed more background noise that lead to the identification of the peaks was difficult. This was assumed to be due to the presence of co-extracted material at higher temperatures. The highest extraction efficiencies were obtained at temperatures ranging from $100^{\circ} \mathrm{C}$ to $140^{\circ} \mathrm{C}$. Based on these results, $120^{\circ} \mathrm{C}$ was selected for verification and optimization of the PLE method. Pressure produced no significant effect on the extraction process. A pressure of 1500 psi has been used in several studies to extract analytes from environmental matrices [22], as the higher pressures are generally applied to keep solvents in their liquid states $[23,24]$.

\subsection{Characterization of the Gel Permeation Chromatography (GPC) Column}

The technique is based on molecular size separation and is primarily used to fractionate and to remove lipids $\left(>500^{\circ} \mathrm{A}\right)$, which elutes first from the column. A standard solution of PCBs was transferred into a gel permeation chromatography (GPC) column packed with $12 \mathrm{~g}$ of SX-3 BioBeads gel (200 - 400 mesh). The column was washed with $25 \mathrm{~mL}$ [hexane:DCM $(1: 1, \mathrm{v} / \mathrm{v})]$ mixture. Then 100 $\mathrm{mL}$ [hexane:DCM $(1: 1, \mathrm{v} / \mathrm{v})]$ solvent mixture was used to elute PCBs. The first $45 \mathrm{~mL}$ was discarded, since all of the lipids were eluted out. The next fraction $(45-100 \mathrm{~mL})$ was collected, since all of the PCBs were completely recovered in this elution. The recoveries of all targeted compounds were in the range of $85.2 \%$ to $102.6 \%$. The advantages of GPC over concentrated sulfuric acid or saponification are its nondestructive nature, which allows large amounts of lipids to be handled, and it has greater applicability for unknown contaminants.

\subsection{Method Validation}

\subsubsection{Quality Control}

Set of experiments were conducted to obtain acceptable and reliable data by using mirex as internal standard (I.SD). The extracted fresh and blank samples were spiked with I.SD. (300 ng/g) before extraction. All analytical data were assessed for compliance with acceptable criteria for method validation; the average of recoveries was required to be within $70 \%-125 \%$. However recoveries obtained for this experiment was generally over $75 \%$ and close to $100 \%$ for most of the PCBs congeners. Thus, the recoveries were considered to be satisfactory, and no interference or serious co-elution was encountered during the evaluation process. A surrogate mixture of ${ }^{13} \mathrm{C}-\mathrm{PCBs}$ containing the following numbers: $101,138,153,180$ and 209 were spiked to the extracted samples, the recoveries obtained for all the cases from A to E were calculated and were found to be above $79 \%$ for most of the ${ }^{13} \mathrm{C}$-PCBs. Table 1, shows the total concentration spiked for each case as well as the range of the recoveries.

\subsubsection{Calibration Graph}

Triplicate injection of $1 \mu \mathrm{l}$ of a set of four standard solutions containing different concentrations of PCBs (21.5, $52.5,109 \mathrm{pg} / \mu \mathrm{l})$ were checked under the optimization conditions of GC/MS (NCI). Internal standard (mirex = $300 \mathrm{pg} / \mu \mathrm{l})$ was added to the standard solutions. The calibration graphs were obtained in the range $21.5 \mathrm{pg} / \mu \mathrm{l}$ to $109 \mathrm{pg} / \mu \mathrm{l}$ with a correlation coefficients $\left(\mathrm{r}^{2}\right)$ exceeding 0.996 for most of the PCBs compounds. The correlation coefficients $\left(\mathrm{r}^{2}\right)$ were satisfactory in the concentration range assayed.

The results obtained for the retention times were acceptable over sets of standards and samples that were studied throughout the experiment. Table 2, represents the calibration data, correlation coefficient $\left(\mathrm{r}^{2}\right)$, regression equations, calibration range, retention times, limit of detections and limit of quantitation for the group of PCBs were analyzed by NCI mode.

\subsubsection{Limit of Detection (LOD) and Limit of Quantitation (LOQ)}

The limit of detections (LODs) were obtained as the compound concentration that cause a peak height equal to three times the baseline noise, whereas the limit of quantitations (LOQs) were obtained as the compound concentration that cause a peak height equal to ten times the baseline noise. Thus LODs and LOQs obtained for PCBs using these conditions are presented in Table 2, and the values were found to be between $0.01 \mathrm{ng} / \mathrm{g}(\mathrm{w} / \mathrm{w})$ to 0.23 $\mathrm{ng} / \mathrm{g}(\mathrm{w} / \mathrm{w})$ and $0.03 \mathrm{ng} / \mathrm{g}(\mathrm{w} / \mathrm{w})$ to $0.93 \mathrm{ng} / \mathrm{g}(\mathrm{w} / \mathrm{w})$ for LODs and LOQs, respectively.

\subsubsection{Precision and Accuracy}

The precision of the proposed method is expressed in terms of relative standard deviation (RSD). Wet fish sample was spiked at three different levels of PCBs standards (21.5 ng/g, $52.5 \mathrm{ng} / \mathrm{g}, 109 \mathrm{ng} / \mathrm{g})$. Repeatability was performed five times $(n=5)$ in the same days under the same conditions. The calculated values showed that the relative standard deviations (RSDs) for most of PCBs compounds were ranging between $0.51 \%$ and $17.4 \%$. Reproducibility for PCBs was ranging from $75.2 \%$ to $103.2 \%$, with RSDs between $1.8 \%$ and $22.6 \%$.

\subsection{Concentrations of PCBs in Fish Samples}

The fish samples were collected from Kuwait's fish mar- 
Table 2. Calibration data, correlation coefficient $\left(r^{2}\right)$, regression equations, calibration range, retention times, LOD and LOQ, for the different PCBs-congeners analyzed by NCI mode.

\begin{tabular}{|c|c|c|c|c|c|c|c|c|c|}
\hline \multirow{2}{*}{ PCBs } & \multirow{2}{*}{$\begin{array}{c}\text { Correl. } \\
\text { Coeff. }\left(\mathrm{r}^{2}\right)\end{array}$} & \multirow{2}{*}{$\begin{array}{l}\text { Regress. } \\
\text { Equation }\end{array}$} & \multirow{2}{*}{$\begin{array}{l}\text { Calib. range } \\
(\mathrm{pg} / \mu \mathrm{l})\end{array}$} & \multicolumn{3}{|c|}{$\begin{array}{l}\text { Retention time, min } \\
\quad \pm \text { S.D. }(n=3)\end{array}$} & \multirow{2}{*}{$\begin{array}{c}\text { LOD } \\
\text { (ng/g) } \\
-\end{array}$} & \multirow{2}{*}{$\begin{array}{c}\text { LOQ } \\
\text { (ng/g) } \\
-\end{array}$} & \multirow{2}{*}{$\begin{array}{c}\mathrm{m} / \mathrm{z} \\
-\end{array}$} \\
\hline & & & & $21.5(\mathrm{pg} / \mu \mathrm{l})$ & $54.5(\mathrm{pg} / \mu \mathrm{l})$ & $109(\mathrm{pg} / \mu \mathrm{l})$ & & & \\
\hline 74 & 1.000 & $3.89 \mathrm{e}-0.001$ & $21.5-109$ & $17.53 \pm 0.09$ & $17.46 \pm 0.01$ & $17.56 \pm 0.01$ & 0.02 & 0.06 & $290 / 292$ \\
\hline 70 & 1.000 & $7.63 e-001$ & $21.5-109$ & $17.66 \pm 0.01$ & $17.63 \pm 0.01$ & $17.63 \pm 0.01$ & 0.01 & 0.03 & $290 / 292$ \\
\hline 101 & 0.998 & $1.12 \mathrm{e}+000$ & $21.5-109$ & $18.92 \pm 0.01$ & $18.91 \pm 0.01$ & $18.92 \pm 0.01$ & 0.09 & 0.32 & $326 / 328$ \\
\hline 99 & 1.000 & $5.07 \mathrm{e}-000$ & $21.5-109$ & $19.19 \pm 0.01$ & $19.18 \pm 0.0$ & $19.18 \pm 0.0$ & 0.01 & 0.04 & $326 / 328$ \\
\hline 87 & 0.995 & $6.57 \mathrm{e}-001$ & $21.5-109$ & $20.38 \pm 0.0$ & $20.36 \pm 0.01$ & $20.37 \pm 0.01$ & 0.03 & 0.09 & $326 / 328$ \\
\hline 110 & 0.997 & $1.02 \mathrm{e}+000$ & $21.5-109$ & $20.99 \pm 0.01$ & $20.98 \pm 0.0$ & $20.97 \pm 0.0$ & 0.20 & 0.68 & $326 / 328$ \\
\hline 151 & 0.996 & $8.43 e+000$ & $21.5-109$ & $21.77 \pm 0.0$ & $21.76 \pm 0.0$ & $21.76 \pm 0.0$ & 0.23 & 0.78 & $326 / 328$ \\
\hline 149 & 0.995 & $2.14+\mathrm{e} 000$ & $21.5-109$ & $22.62 \pm 0.02$ & $22.61 \pm 0.01$ & $22.61 \pm 0.0$ & 0.16 & 0.52 & $360 / 362$ \\
\hline 118 & 0.995 & $7.91 \mathrm{e}+000$ & $21.5-109$ & $22.87 \pm 0.01$ & $22.82 \pm 0.0$ & $22.81 \pm 0.01$ & 0.02 & 0.05 & $326 / 328$ \\
\hline 153 & 0.995 & $1.23 \mathrm{e}+001$ & $21.5-109$ & $24.63 \pm 0.28$ & $24.61 \pm 0.02$ & $24.61 \pm 0.01$ & 0.10 & 0.34 & $360 / 362$ \\
\hline 105 & 1.000 & $1.43 e+000$ & $21.5-109$ & $24.82 \pm 0.02$ & $24.94 \pm 1.74$ & $24.92 \pm 0.02$ & 0.28 & 0.93 & $326 / 328$ \\
\hline 138 & 1.000 & $7.51 \mathrm{e}+000$ & $21.5-109$ & $27.19 \pm 0.01$ & $26.15 \pm 0.08$ & $27.16 \pm 0.01$ & 0.04 & 0.15 & $360 / 362$ \\
\hline 132 & 0.996 & $3.98 \mathrm{e}+000$ & $21.5-109$ & $27.41 \pm 0.0$ & $27.34 \pm 0.01$ & $27.38 \pm 0.01$ & 0.03 & 0.09 & $360 / 362$ \\
\hline 187 & 0.995 & $5.61 \mathrm{e}-000$ & $21.5-109$ & $29.02 \pm 0.01$ & $29.00 \pm 0.01$ & $29.00 \pm 0.01$ & 0.04 & 0.13 & $360 / 362$ \\
\hline 183 & 0.996 & $5.57 \mathrm{e}+000$ & $21.5-109$ & $29.60 \pm 0.01$ & $29.58 \pm 0.02$ & $29.58 \pm 0.01$ & 0.02 & 0.06 & $394 / 396$ \\
\hline 128 & 1.000 & $6.57 e+000$ & $21.5-109$ & $30.17 \pm 0.01$ & $30.12 \pm 0.01$ & $30.12 \pm 0.01$ & 0.02 & 0.07 & $360 / 362$ \\
\hline 177 & 0.994 & $4.36 \mathrm{e}+000$ & $21.5-109$ & $32.29 \pm 0.01$ & $32.28 \pm 0.01$ & $32.29 \pm 0.01$ & 0.04 & 0.15 & $394 / 396$ \\
\hline 171 & 0.993 & $4.91 \mathrm{e}+000$ & $21.5-109$ & $32.75 \pm 0.01$ & $32.73 \pm 0.01$ & $32.73 \pm 0.01$ & 0.03 & 0.10 & $394 / 396$ \\
\hline 156 & 1.000 & $1.02 \mathrm{e}+000$ & $21.5-109$ & $33.01 \pm 0.0$ & $32.96 \pm 0.01$ & $32.95 \pm 0.02$ & 0.21 & 0.69 & $360 / 362$ \\
\hline 180 & 0.996 & $6.02 \mathrm{e}+000$ & $21.5-109$ & $34.59 \pm 0.01$ & $34.58 \pm 0.01$ & $34.57 \pm 0.0$ & 0.05 & 0.15 & $394 / 396$ \\
\hline 191 & 0.994 & $6.4 \mathrm{e}+000$ & $21.5-109$ & $35.15 \pm 0.01$ & $35.14 \pm 0.02$ & $35.13 \pm 0.01$ & 0.01 & 0.04 & $394 / 396$ \\
\hline 169 & 0.999 & $7.05 e+000$ & $21.5-109$ & $36.49 \pm 0.01$ & $36.43 \pm 0.0$ & $36.41 \pm 0.02$ & 0.01 & 0.05 & $360 / 362$ \\
\hline 170 & 0.994 & $5.13 e+000$ & $21.5-109$ & $36.91 \pm 0.01$ & $36.89 \pm 0.0$ & $36.89 \pm 0.01$ & 0.04 & 0.14 & $394 / 396$ \\
\hline 201 & 0.993 & $4.86 \mathrm{e}+000$ & $21.5-109$ & $37.57 \pm 0.0$ & 37.560 .01 & $37.56 \pm 0.01$ & 0.03 & 0.10 & $394 / 396$ \\
\hline 208 & 0.993 & $4.1 \mathrm{e}+000$ & $21.5-109$ & $39.87 \pm 0.0$ & $39.86 \pm 0.0$ & $39.86 \pm 0.0$ & 0.02 & 0.07 & $462 / 464$ \\
\hline 194 & 0.993 & $1.02 \mathrm{e}+001$ & $21.5-109$ & $41.21 \pm 0.01$ & $41.20 \pm 0.01$ & $41.20 \pm 0.0$ & 0.09 & 0.33 & $428 / 430$ \\
\hline 205 & 0.994 & $1.05 \mathrm{e}+001$ & $21.5-109$ & $41.50 \pm 0.0$ & $41.49 \pm 0.0$ & $41.49 \pm 0.01$ & 0.08 & 0.25 & $428 / 430$ \\
\hline 206 & 0.993 & $8.42 \mathrm{e}+000$ & $21.5-109$ & $43.28 \pm 0.03$ & $43.27 \pm 0.03$ & $43.27 \pm 0.0$ & 0.01 & 0.04 & $462 / 464$ \\
\hline 209 & 0.993 & $6.08 \mathrm{e}+000$ & $21.5-109$ & $44.85 \pm 0.01$ & $44.83 \pm 0.01$ & $44.84 \pm 0.01$ & 0.01 & 0.03 & $496 / 498$ \\
\hline
\end{tabular}


ket and tested by the presented method in order to evaluate the levels of PCBs compounds. The PCBs levels in fish samples were ranging from $0.81 \mathrm{ng} / \mathrm{g}$ to $4.46 \mathrm{ng} / \mathrm{g}$ $(\mathrm{w} / \mathrm{w})$ that is in agreement with the levels evaluated by the previously published two methods $[25,26]$. The levels obtained from the two methods were as follows: 0.76 $5.72 \mathrm{ng} / \mathrm{g}(\mathrm{w} / \mathrm{w})$ and $0.44-2.53 \mathrm{ng} / \mathrm{g}(\mathrm{w} / \mathrm{w})$, for method [25] and method [26], respectively. Moreover, comparison of the levels obtained in this study with those obtained by Yang from China are equal to $3.77 \mathrm{ng} / \mathrm{g}(\mathrm{w} / \mathrm{w})$ in fish [27], indicating that the levels obtained in this study are comparative to the levels obtained by other methods. Based on this study, total $\sum$ PCBs concentrations in Kuwait's seafood are deemed to be generally not high.

\section{Conclusion}

The comprehensive method was established, based on PLE extraction, clean-up of PCBs extracts from fish samples with different adsorbent materials. The detected PCBs congeners showed good accuracy, precision, and linearity range in the method studied. The advantage derived from using NCI source along with GC/MS detection is being capable of obtaining high selective method, resulting in eliminating the interferences of substances from sample matrices. Furthermore, allowing detection of PCBs in fish tissue at low ng/g levels. This method provides better recoveries when using any of the selected adsorbent with the clean-up solvent mixture. The relative standard deviation of the method was acceptable and within the required range. PLE offers the advantage of reducing the amount of organic solvent consumed and it can be easily automated.

\section{REFERENCES}

[1] F. Wania and D. Mackay, "Tracking the Distribution of Persistent Organic Pollutant," Environmental Science and Technology, Vol. 30, No. 9, 1996, pp. 390A-396A. doi:10.1021/es962399q

[2] E. Bjorklund, T. Nilson and S. Bowadt, "Pressurized Liquid Extraction of Persistent Organic Pollutants in Environmental Analysis," Trends in Analytical Chemistry, Vol. 19, No. 7, 2000, pp. 434-445. doi:10.1016/S0165-9936(00)00002-9

[3] H. Giergielewicz-Mozajska, L. Dabrowski and J. Namiesnik, "Accelerated Solvent Extraction (ASE) in the Analysis of Environmental Solid Samples-Some Aspects of Theory and Practice," Critical Review in Analytical Chemistry, Vol. 31, No. 3, 2001, pp. 149-165. doi: $10.1080 / 20014091076712$

[4] A. Muller, E. Bjorklund and C. Von Holst, "On-Line Clean-Up of Pressurized Liquid Extracts for the Determination of Polychlorinated Biphenyls in Feedingstuffs and Food Matrices Using Gas Chromatography-Mass Spectrometry," Journal of Chromatography A, Vol. 925, No. 1-2, 2001, pp. 197-205. doi:10.1016/S0021-9673(01)01028-7

[5] E. Bjorklund, A. Muller and C. Von Holst, "Comparison of Fat Retainers in Accelerated Solvent Extraction for the Selective Extraction of PCBs from Fat-Containing Samples," Analytical Chemistry, Vol. 73, No. 16, 2001, pp. 4050-4053. doi:10.1021/ac010178j

[6] S. Sporring and E. Bjorklund, "Selective Pressurized Liquid Extraction of Polychlorinated Biphenyls from FatContaining Food and Feed Samples: Influence of Cell Dimensions, Solvent Type, Temperature and Flush Volume," Journal of Chromatography A, Vol. 1040, No. 2, 2004, pp. 155-161. doi:10.1016/j.chroma.2004.04.022

[7] B. E. Richter, "Current Trends and Developments in Sample Preparation," LCGC, Vol. 17, No. 6S, 1999, pp. S22S28.

[8] USEPA Method, "Pressurized Liquid Extraction Test Methods for Evaluating Solid Waste," US Environmental Protection Agency US Environmental Protection Agency, Vol. 3545, Washington DC, 1995.

[9] M. M. Schantz, J. J. Nichols and S. A. Wise, "Evaluation of Pressurized Fluid Extraction for the Extraction of Environmental Matrix Reference Materials," Analytical Chemistry, Vol. 69, No. 20, 1997, pp. 4210-4219. doi:10.1021/ac970299c

[10] B. E. Richter, B. A. Jones, J. L. Ezzel, N. L. Porter, N. Avdalovic and C. Pohl, "Accelerated Solvent Extraction: A Technique for Sample Preparation," Analytical Chemistry, Vol. 68, No. 6, 1996, pp. 1033-1039. doi:10.1021/ac9508199

[11] J. J .L. F. Moreno, F. J. A. Liebanas, A. G. Frenich and J. L. M. Vidal, "Evaluation of Different Sample Treatments for Determining Pesticide Residues in Fat Vegetable Matrices like Avocado by Low-Pressure Gas Chromatography-Tandem Mass Spectrometry," Journal of Chromatography A, Vol. 1111, No. 1, 2006, pp. 97-105. doi:10.1016/j.chroma.2006.01.108

[12] P. Suchan, J. Pulkrabova, J. Hajslova and V. Kocourek, "Pressurized Liquid Extraction in Determination of Polychlorinated Biphenyls and Organochlorinated Pesticides in Fish Samples," Analytica Chimica Acta, Vol. 520, No. 1-2, 2004, pp. 193-200. doi:10.1016/j.aca.2004.02.061

[13] K. Kitamura, Y. Takazawa, S. Hashimoto, J.-W. Choi, H. Ito and M. Morita, "Effective Extraction Method for Dioxin Analysis from Lipid-Rich Biological Matrices Using a Combination of Pressurized Liquid Extraction and Dimethyl Sulfoxide/Acetonitrile/Hexane Partitioning," Analytica Chimica Acta, Vol. 512, No. 1, 2004, pp. 27-37. doi:10.1016/j.aca.2004.02.040

[14] E. Martinez, M. Gros, S. Lacorte and D. Barcelo, "Simplified Procedures for the Analysis of Polycyclic Aromatic Hydrocarbons in Water, Sediments and Mussels," Journal of Chromatography A, Vol. 1047, No. 2, 2004, pp. 181188.

[15] K. Saito, A. Sjodin, C. D. Sandau, M. D. Davis, H. Nakazawa, Y. Matsuki and D. G. Patterson Jr., "Develop- 
ment of a Accelerated Solvent Extraction and Gel Permeation Chromatography Analytical Method for Measuring Persistent Organohalogen Compounds in Adipose and Organ Tissue Analysis," Chemosphere, Vol. 57, No. 5, 2004, pp. 373-381. doi:10.1016/j.chemosphere.2004.04.050

[16] Q. Jiang, N. Hanari, Y. Miyake, T. Okazawa, R. K. F. Lau, K. Chen, B. Wyrzykowska, M. K. So, N. Yamashitab and P. K. S. Lam, "Health Risk Assessment for Polychlorinated Biphenyl, Polychlorinated Dibenzo-p-Dioxins and Dibenzofurans, and Polychlorinated Naphthalenes in Seafood from Guangzhou and Zhoushan, China," Environmental Pollutant, Vol. 148, No. 1, 2007, pp. 31-39. doi:10.1016/j.envpol.2006.11.002

[17] K. S. Kumar, K. Kannan, J. P. Giesy and S. Masunaga, "Distribution and Elimination of Polychlorinated Dibenzo-p-Dioxins, Dibenzofurans, Biphenyls, and $p, p$ '-DDE in Tissues of Bald Eagles from the Upper Peninsula of Michigan," Environmental Science and Technology, Vol. 36, No. 13, 2002, pp. 2789-2796. doi:10.1021/es0114660

[18] M. K. So, X. Zhaug, J. P. Giesy, C. N. Fung, H. W. Fong, J. Zheng, M. J. Kramer, H. Yoo and P. K. S. Lam, "Organochlorines and Dioxin-Like Compounds in GreenLipped Mussels Perna viridis from Hong Kong Mariculture Zones," Marine Pollutant Bulletin, Vol. 51, No. 8-12, 2005, pp. 677-687. doi:10.1016/j.marpolbul.2005.06.004

[19] S. Jayaraman, R. J. Pruell and R. Mc Kinney, "Extraction of Organic Contaminants from Marine Sediments and Tissues Using Microwave Energy," Chemosphere, Vol. 44, No. 2, 2001, pp. 181-191. doi:10.1016/S0045-6535(00)00201-0

[20] A. Hubrt, K. D. Wenzel, W. Engelworld and G. Shuurmann, "Accelerated Solvent Extraction-More Efficient Extraction of POPs and PAHs from Real Contaminated Plant and Soil Samples," Reviewers in Analytical Chemistry, Vol. 20, No. 2, 2001, pp. 101-144.

[21] V. R. Meyer, "Practical High-performance liquid chro- matography”, 2nd Edition, Frankfurt, 1996.

[22] M. Numata, T. Yarita, Y. Aoyagi, Y. Tsuda, M. Yamazaki, A. Takatsu, K. Ishikawa, K. Chiba and K. Okamaoto, "Sediment Certified Reference Materials for the Determination of Polychlorinated Biphenyls and Organochlorine Pesticides from the National Metrology Institute of Japan (NMIJ)," Analytical Bioanalytical Chemistry, Vol. 387, No. 7, 2007, pp. 2313-2323. doi:10.1007/s00216-006-0691-z

[23] J. J. Ramos, C. Dietz, M. J. Gonzalez and L. Ramos, "Miniaturized Selective Pressurized Liquid Extraction of Polychlorinated Biphenyls from Foodstuffs," Journal of Chromatography A, Vol. 1152, No. 1-2, 2007, pp. 254-261. doi:10.1016/j.chroma.2006.11.097

[24] U. N. Fidalgo, G. E. Blanco and M. A. Sanz, "Sample Handling Strategies for the Determination of Persistent Organic Contaminants from Biota Samples," Analytica Chimica Acta, Vol. 590, No. 1, 2007, pp. 1-16. doi:10.1016/j.aca.2007.03.004

[25] M. I. H. Helaleh and A. Al-Rashdan, "Application of Automated Pressurized Liquid Extraction (PLE) and Power $^{\text {prep }}$ Clean-Up System for the Analysis of Polyhydrocarbons, Organochlorinated Pesticides and Polychlorinated Biphenyls in Marine Samples," Analytical Methods, 2012, In Press.

[26] Murad I. H. Helaleh, A. Al-Rashdan and A. Ibtisam, "Simultaneous Analysis of Organochlorinated Pesticides (OCPs) and Polychlorinated Biphenyls (PCBs) from Marine Samples Using Automated Pressurized Liquid Extraction (PLE) and Power Prep ${ }^{\mathrm{TM}}$ Clean-Up," Talanta, Vol. 94, 2012, pp. 44-49. doi:10.1016/j.talanta.2012.02.031

[27] N. Yang, M. Matsuda, M. Kawano and T. Wakimoto, "PCBs and Organochlorine Pesticides (OCPs) in Edible Fish and Shellfish from China," Chemosphere, Vol. 63, No. 8, 2006, pp. 1342-1352. doi:10.1016/j.chemosphere.2005.09.029 